\title{
SISTEMA NACIONAL DE EDUCAÇÃO: OS ARRANJOS NA COOPERAÇÃO, PARCERIA E COBIÇA SOBRE O FUNDO PÚBLICO NA EDUCAÇÃO BÁSICA
}

\author{
Carlos Augusto AbicaliL ${ }^{*}$
}

\begin{abstract}
RESUMO: O presente artigo objetiva explicitar novas formas de disputa pelo fundo público ampliado para a educação nacional, na oportunidade de desenho institucional do Sistema Nacional de Educação em formatação a partir do Plano Nacional de Educação, suas diretrizes, metas e estratégias para a década. Descrevem-se as recém-criadas estruturas de gestão interfederativa, normas complementares emanadas do Conselho Nacional de Educação e ações institucionais do Ministério da Educação nesse novo contexto. Destacando narrativas dos próprios atores sociais do chamado terceiro setor, apresenta suas estratégias para conformar um arcabouço jurídico normativo que permita atuar diretamente sobre os recursos federais do Fundo de Manutenção e Desenvolvimento da Educação Básica e Valorização do Magistério (Fundeb) e do Fundo Nacional de Desenvolvimento da Educação (FNDE), valendo-se da oferta de assessorias à gestão pública municipal por meio dos Arranjos de Desenvolvimento da Educação.

Palavras-chave: Cooperação interfederativa em educação. Gestão empresarial de fundo público na educação básica. Municipalização e privatização da gestão educacional.
\end{abstract}

\section{National System of Education: THE ARRANGEMENTS IN COOPERATION, PARTNERSHIP AND THE GREED OVER PUBLIC FUNDS IN BASIC EDUCATION}

ABSTRACT: The present article aims at clarifying the new forms of dispute over public funds extended to national education, due to an institutional design of the National System of Education being foulated based on the National Education Plan, its guidelines, goals and strategies for the decade. It describes the newly created Intergovernmental management structures, complementary regulations emanating from the National Council of Education and institutional measures of the Ministry of Education in this new context. Highlighting narratives of the very social actors in the so called third sector, it presents their

Liderança do Governo no Congresso Nacional. Brasília (DF) -Brasil.

Contato com o autor: <caabiccalil@uol.com.br> 
strategies to conform to a normative legal structure that allows direct actions over federal funds from the National Fund for Maintenance and Development of Basic Education and Education Professionals Valorization (Fundeb) and the National Fund for Education Development (FNDE), taking advantage of the possibility of offering municipal public education management consultancy by means of the Arrangements for the Development of Education.

Key words: Intergovernmental cooperation in Education. Organizational governance of Basic Education public funds. Municipalization and privatization of educational management.

\section{SySTÈmE NATIONAL D'ÉDUCATION: LES DISPOSITIONS EN COOPÉRATION, PARTENARIAT ET AVIDITÉ SUR LE FOND PUBLIC DANS L'ENSEIGNEMENT DE BASE}

RÉSUMÉ: Le présent article vise expliciter de nouvelles formes de conflit par le fond public agrandi pour l'éducation nationale, dans l'occasion du projet institutionnel du Système National d'Éducation en formation à partir du Plan National d'Éducation, de leurs directives, d'objectifs et des stratégies pendant la décennie. Il s'agit de décrire les nouvelles structures de gestion d'administration fédérale, les normes complémentaires émanées du Conseil National d'Éducation et les actions institutionnelles du Ministère de l'Éducation Nationale dans ce nouveau contexte. En détachant des récits des acteurs sociaux eux-mêmes du troisième secteur, il présente leurs stratégies pour former un plan juridique normatif qui permet d'agir directement sur les ressources fédérales du Fond de Mantient et Développement de l'Éducation Basique et la Valorisation de l'Enseignement (Fundeb) et du Fond National de Développement de l'Éducation (FNDE), en souligant l'offre de consulting à la gestion publique municipale à travers les Dispositions de Développement de l'Education.

Mots-clés: Coopération inter féderative dans l'éducation. Gestion d'entreprise de fond public dans l'éducation basique. Municipalisation et privatisation de la gestion scolaire.

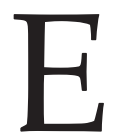

ntranhado no federalismo de cooperação (ARAUJO, 2010), o Sistema Nacional de Educação (SNE) situa-se num inédito estágio de conformação desde sua proclamação no Manifesto dos Pioneiros da Escola Nova. A partir do Plano Nacional de Educação (PNE), em debate no Congresso Nacional, ao mesmo tempo em que se expandem o direito público subjetivo e a obrigatoriedade na educação básica (ABCALIL, 2010), há a inclusão da União na responsabilidade solidária para fazer frente às obrigações do Estado brasileiro diante do direito público subjetivo ampliado. Segundo a Emenda Constitucional (EC) n. 59/2009:

Art. $211-[\ldots]$.

$\S 4^{\circ}$. Na organização de seus sistemas de ensino, a União, os Estados, o Distrito Federal e os Municípios definirão formas de colaboração, de modo a assegurar a universalização do ensino obrigatório. (BRASIL, 1988; grifo nosso) 
Essa consideração inicial não é desprovida de significação importante para dar segmento e consequência às disposições alteradas anteriormente na ampliação do financiamento compartilhado da educação básica e da abertura para a regulamentação - em lei complementar específica - da cooperação federativa prevista no artigo 23 da Constituição Federal, na redação dada pela EC n. 53/2006:

Art. 23 - É competência comum da União, dos Estados, do Distrito Federal e dos Municípios:

$\mathrm{V}$ - promover o acesso à cultura, à educação e à ciência;

Parágrafo Único - Leis complementares fixarão as normas para a cooperação entre a União e os Estados, o Distrito Federal e os Municípios, tendo em vista o equilíbrio do desenvolvimento e o bem-estar em âmbito nacional. (BRASIL, 1988)

Há quem trate como mera minudência nominalista ou apego à tradição legalista. Porém, mesmo quem sustenta a tese de que o SNE está dado a partir da concepção de princípios e ordenamentos constitucionais e de diretrizes e bases da educação nacional em lei sugere uma repartição das tarefas operacionais (por exemplo: transporte, alimentação escolar e manutenção de prédios como competências municipais; contratação de profissionais da educação básica como competência dos estados; e formação inicial e continuada realizada pela colaboração entre os estados e a União) e aposta nessa oportunidade para estabelecer uma nova pactuação das responsabilidades (SAVIANI, 2011a), que, para Saviani, prescinde de lei complementar e, para este autor, a reivindica, tendo em vista a ocorrência real da organização e manutenção de redes públicas e compromissos de manutenção e desenvolvimento de ensino já existentes nos três âmbitos.

À luz do novo ordenamento constitucional, o SNE é derivação do PNE, conforme se pode ler:

Art. 214. A lei estabelecerá o plano nacional de educação, de duração decenal, com o objetivo de articular o Sistema Nacional de Educação em regime de colaboração e definir diretrizes, objetivos, metas e estratégias de implementação para assegurar a manutenção e desenvolvimento do ensino em seus diversos níveis, etapas e modalidades, por meio de ações integradas dos poderes públicos das diferentes esferas federativas que conduzam a:

I - erradicação do analfabetismo;

II - universalização do atendimento escolar;

III - melhoria da qualidade do ensino;

IV - formação para o trabalho;

V - promoção humanística, científica e tecnológica do País.

VI - estabelecimento de meta de aplicação de recursos públicos em educação como proporção do produto interno bruto. (BRASIL, 1988) 
Há, pois, um imperativo constitucional, com propósitos descritos nos incisos I a VI, cujo método supõe ações integradas dos poderes públicos das diferentes esferas administrativas e cujo processo é resultante da colaboração em torno de um plano nacional definido por diretrizes, objetivos, metas e estratégias de implementação para assegurar o direito à educação e seus desdobramentos nos planos estaduais, distrital e municipais consentâneos. Impossível, assim, dissociar o Plano de sua capacidade de articular o Sistema.

Igualmente, é imperativo resguardar o conceito de SNE com as características intrínsecas ao seu caráter ontológico, essencialmente público e unitário, considerada a variedade de seus elementos e a sua unidade coerente e operante (SAVIANI, 2011b). Este mesmo autor (2011a) relaciona quatro grandes campos de obstáculos à efetivação do sistema nacional, redimensionados, agora, pelas deliberações da Conferência Nacional de Educação (Conae) e pela tramitação do Projeto de Lei da Câmara (PLC) n. 103/2012 (PNE), no Senado Federal.

Além disso, ainda que concordemos que o objeto central da disputa para a implantação do SNE esteja menos na forma de organização e mais na concepção de educação (GRACINDO, 2010), sem reduzir o debate ao nominalismo ou ao positivismo jurídico, impõe-se a atenção em relação ao vigor do movimento social e ao rigor da lei na formulação da política. Vale considerar que é tal a centralidade dessa disputa conceitual que o próprio Conselho de Desenvolvimento Econômico e Social da Presidência da República (CDES) listou-a entre os principais desafios que o Brasil terá de enfrentar (SPELLER, 2010), notadamente, na consideração dos dados educacionais e fiscais relacionados pelo Observatório da Equidade.

Ganham destaque, por outro lado, as formulações de avanço na composição de instâncias interfederativas de decisão, formulação e decisão operacional (ABRÚCIO, 2010) - mais visível como pleito e inovação no nível da educação básica (MARTINS, 2011) e de controle, acompanhamento e participação democrática. No entanto, além das medidas de coordenação federativa, necessário será avançar na normatização das responsabilidades compartilhadas entre os entes federados e - em perspectiva - os ordenadores do financiamento e da democratização da gestão da educação no PNE (DOURADO; AMARAL, 2011). Assim, é possível perceber passos marcantes da trajetória mais recente que confirmam a oportunidade fecunda desse momento histórico: não ficarmos trancados nos fatos, mas (a)diante deles. Por essa razão, entre outras, não é concebível a formulação do PNE em lei que não faça qualquer menção ao SNE. Quando muito, o texto do PLC n. 103/2012, no Senado Federal, menciona que a consecução das metas e a implementação das estratégias deverão ser efetivadas em regime de colaboração entre a União, os estados, o Distrito Federal e os municípios, "não elidindo a adoção de medidas adicionais em âmbito local ou de instrumentos jurídicos que formalizem a cooperação entre os entes federados, 
podendo ser complementados por mecanismos nacionais e locais de coordenação e colaboração recíproca" (CONAE, 2010a, art. $\left.7^{\circ}, \S^{\S} 1^{\circ}\right)$.

É inadequado pensar que o imperativo constitucional do sistema nacional possa ser atendido por esse dispositivo tão impreciso. Menos inteligível ainda é considerar que o próprio Projeto de Lei (PL) institui o Fórum Nacional de Educação (FNE) e as Conaes, com atribuições específicas sobre o PNE. Essas constatações levaram à apresentação de emendas ao $\mathrm{PL}$, com muitas feições distintas, sobre a instituição, ou à caracterização mais consistente do SNE.

Evidentemente, uma lei de plano plurianual não é a lei do sistema nacional. Menos ainda se esta lei for equivalente à regulação da cooperação federativa para assegurar a consecução dos princípios, das diretrizes e das metas concernentes à ação pública articulada para a garantia de direitos universais. Os substitutivos sucessivos do PL do PNE, por sua vez, trouxeram versões distintas dessa tensão.

Merece destaque, antes, a Comissão Intergovernamental para o Financiamento da Educação Básica de Qualidade, no âmbito do Fundo de Manutenção e Desenvolvimento da Educação Básica e de Valorização dos Profissionais da Educação (Fundeb) (ABRÚCIO, 2010). Além da novidade por sua conformação interfederativa, está a sua competência sobre os recursos complementares da parcela da União destinada a "programas direcionados à melhoria da qualidade" (BRASIL, 2007).

Art. $7^{\circ}$. Parcela da complementação da União, a ser fixada anualmente pela Comissão Intergovernamental de Financiamento para a Educação Básica de Qualidade instituída na forma da Seção II do Capítulo III desta Lei, limitada a até 10\% (dez por cento) de seu valor anual, poderá ser distribuída para os Fundos por meio de programas direcionados para a melhoria da qualidade da educação básica, na forma do regulamento.

Considerada a complementação adicional da União para o ano de 2012, através da Portaria do MEC n. 344, de 24 de abril de 2013, essa parcela alcançou a maior parte do montante que foi distribuído ( $\mathrm{R}$ \$1,3 bilhão), cumprindo a Resolução n. 7, de 26 de abril de 2012, daquela Comissão Intergovernamental. A mesma destinação está prevista em R \$ 1,07 bilhão para 2013. Esses recursos são transferências diretas da União, adicionais aos que os estados e municípios já dispõem para a manutenção e desenvolvimento da educação básica pública, cuja destinação legal está considerada na LDB:

Art. 70. Considerar-se-ão como de manutenção e desenvolvimento do ensino as despesas realizadas com vistas à consecução dos objetivos básicos das instituições educacionais de todos os níveis, compreendendo as que se destinam a:

I - remuneração e aperfeiçoamento do pessoal docente e demais profissionais da educação;

II - aquisição, manutenção, construção e conservação de instalações e equipamentos necessários ao ensino; 


\begin{abstract}
III - uso e manutenção de bens e serviços vinculados ao ensino;
IV - levantamentos estatísticos, estudos e pesquisas visando precipuamente ao aprimoramento da qualidade e à expansão do ensino;

$\mathrm{V}$ - realização de atividades-meio necessárias ao funcionamento dos sistemas de ensino;

VI - concessão de bolsas de estudo a alunos de escolas públicas e privadas;
\end{abstract}

VII - amortização e custeio de operações de crédito destinadas a atender ao disposto nos incisos deste artigo;

VIII - aquisição de material didático-escolar e manutenção de programas de transporte escolar. (BRASIL, 1996; grifos nossos)

A Comissão Intergovernamental deveria observar as condicionalidades exigidas em lei para proferir os critérios de repartição dos recursos adicionais da transferência da União, a saber:

Art. 13. No exercício de suas atribuições, compete à Comissão Intergovernamental de Financiamento para a Educação Básica de Qualidade: [...]

III - fixar anualmente a parcela da complementação da União a ser distribuída para os Fundos, por meio de programas direcionados para a melhoria da qualidade da educação básica, bem como respectivos critérios de distribuição, observado o disposto no art. $7^{\text {}}$ desta Lei;

Parágrafo único. Para a distribuição da parcela de recursos da complementação a que se refere o caput deste artigo aos Fundos de âmbito estadual beneficiários da complementação nos termos do art. $4^{\circ}$ desta Lei, levar-se-á em consideração:

I - a apresentação de projetos em regime de colaboração por Estado e respectivos Municípios ou por consórcios municipais;

II - o desempenho do sistema de ensino no que se refere ao esforço de habilitação dos professores e aprendizagem dos educandos e melhoria do fluxo escolar;

III - o esforço fiscal dos entes federados;

IV - a vigência de plano estadual ou municipal de educação aprovado por lei. (BRASIL, 2007; grifos nossos)

Desconsiderando as condicionalidades legais, a Comissão Intergovernamental abre mão de uma de suas mais relevantes competências, tendo em vista o papel da coordenação de uma política educacional tão fundamental como a de financiamento. Entre as razões recentemente alegadas durante a realização do Fórum de Avaliação do Financiamento da Educação Básica Nacional, entre 2 e 3 de julho de 2013, registrava-se a dificuldade dos entes federativos - que alegavam recursos insuficientes para cumprimento da Lei do Piso Salarial Profissional Nacional - comprovarem efetivamente tal condição mediante as disposições da Portaria do MEC n. 213, de 2 de fevereiro de 2011.

Se consideradas as estatísticas comumente utilizadas para expressar o comprometimento de cada ente federado na manutenção e desenvolvimento da educação 
básica, o Distrito Federal, os estados e municípios somados dispõem de quatro vezes mais recursos dedicados à educação básica do que a União, consideradas as receitas de impostos e do Salário Educação.

Mantida essa proporção nas destinações na soma dos incisos IV, V e VIII do artigo 70 da LDB, tratar-se-ia de uma cifra próxima de $\mathrm{R} \$ 4$ bilhões anuais agregados potencialmente ao complemento da União. Não há informações seguras estratificadas para sua confirmação. Isso demandaria uma pesquisa nacional mais acurada.

$\mathrm{O}$ fato é que tais volumes de recursos potencializam um mercado de $\mathrm{R} \$ 5$ bilhões anuais em consultorias, mobilização social, eventos, seminários, fóruns, programas de formação continuada, de gestão de pessoas, de assessorias pedagógicas e de planejamento, de oficinas didáticas, de organização curricular, de materiais complementares para os chamados currículos estruturados e de suporte pedagógico para preparação de exames massivos, entre outras atividades.

Tais insumos são realizados por contratações pulverizadas entre os 5.570 municípios, os 26 estados e o Distrito Federal para provimento de suas respectivas redes de ensino oficiais. $\mathrm{O}$ risco de descontinuidade contratual e o fracionamento dos volumes resultam em dificuldades operacionais e de segurança de resultados financeiros dos fornecedores. Tais incidências ainda enfrentam a salutar alternância nas administrações derivadas dos processos eleitorais a cada quatro anos, por decisão popular, e dos ajustes político-administrativos no interior de um mesmo período de mandato.

Para a organização dos fornecedores, essa dinâmica derivada do exercício popular do voto é risco adicional no seu negócio especializado em prover insumos educacionais.

A apropriação desses valores adicionais permanece, assim, em disputa pulverizada entre os entes federativos e incluída no rol dos nove estados que recebem complementação federal para cumprimento dos valores mínimos correspondentes às matrículas de cada etapa e modalidade da educação básica. Por outro lado, entes federativos dos outros 17 fundos estaduais e do Distrito Federal não alcançados pela complementação federal questionam a repartição desses recursos para programas de qualidade.

Por diversas vezes, os entes federados são motivados pela imensa gama de fornecedores de tecnologias educacionais (certificadas ou não), anualmente dispostas à venda de assessorias diversas, somadas agora às sofisticadas metodologias e processos de gestão e acompanhamento do Plano de Ação Articulada (PAR), entre inúmeras outras ofertas.

Já é sabido que o mercado editorial brasileiro, para além das isenções tributárias, tem no Programa Nacional do Livro Didático seu principal mantenedor. As 
compras governamentais centralizadas, com a democratização dos processos de escolha pelas escolas após o crivo avaliativo de uma comissão nacional, proveem uma associação do controle público com o volume, a economia de escala na aquisição, na logística, na distribuição e, obviamente, na garantia de mercado com baixíssimo risco. Igualmente, não elimina a conformação do mercado marginal passível da compra direta pelas administrações de redes públicas Brasil a dentro.

Também é notória a percepção da fragilidade das estruturas de administração em boa parte dos municípios e estados brasileiros; por essa razão mesma, a tarefa da União (e dos estados em relação aos municípios) em assegurar a função redistributiva e supletiva quanto ao financiamento da educação básica e prestar a assistência técnica. Essa percepção considerada na Constituição Federal e na própria Lei de Diretrizes e Bases da Educação Nacional também se alargou no interior do chamado Terceiro Setor, com motivações e formas de atuação distintas junto às escolas públicas isoladamente, em redes públicas inteiras, em mais de uma rede pública, muitas vezes.

A ocorrência da sistemática do PAR, a instituição do Plano de Desenvolvimento da Educação e o correspondente Compromisso "Todos pela Educação" coincidiram com a edição dos grandes investimentos públicos e consórcios privados em torno do Programa de Aceleração do Crescimento (PAC). O alto impacto desses empreendimentos, o fortalecimento do controle social, as condicionantes ambientais, sociais, demográficas e culturais, as ações mitigadoras condicionantes e o acompanhamento dos órgãos de controle interno e externo levam a outro patamar de consideração das interações entre as atribuições e capacidades públicas na oferta direta de educação, as demandas do mercado de trabalho, a rede de proteção social, as obrigações dos empreendedores e a (in)capacidade da gestão local de corresponder, em tempo, à vazão dessas respostas.

As disputas de significado da qualidade e da eficiência das políticas educacionais ganham novo status, novos atores, novos alcances. O ordenamento e as limitações da administração pública, entretanto, permanecem praticamente intocados, como a Lei n. 8.666 de 1993 (Licitações Públicas), a Lei Complementar n. 101 de 2000 (Lei de Responsabilidade Fiscal) e a Emenda Constitucional n. 19 de 1998.

Uma atualização importante da estrutura pública na tentativa de reversão do estrangulamento das capacidades públicas, pulverizadas na chamada autonomia federativa, diz respeito ao esforço associativo entre os entes federativos: os consórcios públicos, regulados na forma da Lei n. 11.107 de 2005 e no Decreto n. 6017 de 2007.

O Brasil é uma Federação extremamente desigual. Segundo o Observatório dos Consórcios Públicos e Federalismo: 81\% dos municípios têm no Fundo de Participação dos Municípios (FPM) mais de 50\% de suas receitas; 25\% do PIB se concentram em apenas cinco grandes municípios; 70\% dos municípios têm menos de 20 mil 
habitantes, reúnem $18 \%$ da população nacional, com menos de $20 \%$ de seus orçamentos constituídos por receitas próprias e baixa capacidade de gestão. Esse conjunto de características resulta em precariedade agravada dos serviços públicos.

Esse diagnóstico, que não é recente, já havia motivado a conformação de estruturas de articulação territorial e administrativa diversas, por convênios, acordos, associações com finalidades específicas, consórcios, parcerias, práticas informais. $\mathrm{O}$ avanço do controle sobre as finanças públicas foi determinando aperfeiçoamentos. Alguns desses modos de ação cooperativa ganharam personalidade jurídica de direito privado, submetido ao código civil, gerando, por vezes, suspeição sobre desvio de finalidades para recursos públicos. Não havia norma federal que oferecesse segurança jurídica, tributária e fiscal para tais conformações. Somente em 2007, esse patamar foi alcançado depois de dois anos de debate para regulamentação e em vista dos avanços nas pactuações políticas em curso.

Autarquias e sociedade civil não participam de consórcios públicos. Apenas entes federativos. Podem ser conformados por municípios, por municípios e estados, e, somente neste caso, facultada a participação da União. Trata-se de um novo protagonismo dos estados, reforçando as disposições constitucionais sobre suas competências de coordenação política e ação supletiva, assim como da União e dos estados no ordenamento territorial e na conformação de regiões de desenvolvimento. Em ambos os casos, com enorme capacidade indutora e de participação.

A necessidade premente de ação pública comum no território e sua percepção são decisivas para a execução de políticas públicas em diferentes áreas: saúde, infraestrutura, meio ambiente, planejamento, transporte, informática, educação, turismo, desenvolvimento econômico, desenvolvimento regional, instituição de regiões metropolitanas (somam 36, hoje), tratamento de resíduos sólidos, saneamento, bacias hidrográficas, regiões de fronteira. Inevitavelmente, as conformações associativas e suas finalidades dependem de uma decisão por opção.

Num consórcio público, cada ente federativo aprova em lei própria sua participação, segundo finalidades, compromissos, competências, recursos disponíveis, processos de gestão, de controle e de decisão definidos em comum. A formalização de entidade de direito público e natureza autárquica tem sido prevalente em função das pressões tributárias, fiscais, da lei de licitações, especialmente. Nesse modelo, considerado como de administração indireta com normas específicas, submete-se ao controle externo dos Tribunais de Contas da União e dos Estados e ao acompanhamento continuado dos órgãos do Ministério Público (ver guia de consórcios públicos em: www.caixa.gov.br)

Além dessas observâncias, a organização dos consórcios prevê a realização de assembleias gerais, secretaria executiva com responsabilidades públicas e cíveis, 
grupos de trabalho temáticos, de acordo com suas finalidades definidas, controle social, conselho consultivo e obrigatoriedade de acesso funcional por concurso público, ainda que o regime de contratação seja pela Consolidação das Leis do Trabalho.

O Observatório estima o funcionamento pleno de 688 consórcios públicos no ano de 2013.

No momento em que as pesquisas sobre financiamento da educação indicam a franca expansão dos investimentos públicos em todos os níveis, o vigor das transferências constitucionais, legais e voluntárias, e a previsão de duplicar a proporção do PIB no dispêndio público, a disputa de instituições privadas por acesso ao fundo público e a defesa determinada de seus interesses levam à necessária consideração das suas novas estratégias de intervenção. A melhor distribuição da renda nacional e a promoção de grandes contingentes populacionais à chamada classe média potencializam um mercado consumidor de serviços educacionais e a pressão por formas subsidiadas de oferta e/ou pela intermediação e controle das ações de cooperação por transferência voluntária, ou adição de recursos complementares.

Talvez essa constatação possa oferecer mais luzes para certa compreensão do "atalho silencioso do empresariado para a definição e regulamentação do regime de colaboração" (ARAUJO, 2012) no seu comentário à Resolução n. 1, de 23 de janeiro de 2012.

A emblemática publicação do livro Regime de Colaboração e associativismo territorial brasileiro - arranjos de desenvolvimento da educação (ABRÚCIO; RAMOS, 2012) dá voz a argumentos de diversos agentes envolvidos no debate federativo e na ação de organizações privadas de assessoramento educacional em escala regional e microrregional, notadamente, em atenção aos municípios em variadas regiões brasileiras. Para melhor compreensão da ação programática de alguns desses agentes e instituições, destacamos alguns registros de sua própria autoria.

Competentemente, Fernando Luiz Abrúcio, um dos coordenadores da publicação citada, já no primeiro artigo, considera:

O fenômeno do associativismo territorial é muito importante nas federações, envolvendo, necessariamente, a aliança formal ou informal entre governos que estejam em territórios contíguos, associativismo territorial para a coordenação intergovernamental, podendo ter também a participação vertical de outros entes federativos. (ABRÚCIO, 2012, p. 22 e 23)

Não resta dúvida de que o recurso à aliança entre governos para a ação coordenada é uma solução importante para a consecução de políticas públicas de alcance universal, particularmente quando envolve competências concorrentes dos entes federativos no exercício do dever público e na garantia de direitos civis. No caso da 
educação, como já visto, é um imperativo constitucional. Não obstante tal imperativo, o autor menciona destacadamente fatores de relevância objetiva.

\begin{abstract}
Sua relevância se deve a três aspectos. O primeiro está relacionado à solução de questões envolvendo espaços geográficos que vão além de uma única jurisdição. Exemplos: problemas vinculados aos recursos hídricos ou aos transportes metropolitanos. Outra função do associativismo territorial é dividir tarefas diferentes entre governos locais vizinhos, de modo que a união sirva para somar esforços em prol de um objetivo comum ou para distribuir atividades entre os que têm mais condições de exercê-las em um determinado território, cabendo aos demais pactuantes contribuir com auxílio financeiro, como ocorre em certos consórcios de Saúde, que oferecem serviços de maior complexidade. Exemplos: compra de merenda ou de ônibus escolares. A união em torno de projetos de desenvolvimento regional é mais um dos aspectos que realçam a importância do associativismo territorial, pois dessa forma pode-se alavancar atividades e setores que terão efeito agregado para todos os governos locais envolvidos no arranjo. (Idem, ibid., p. 23)
\end{abstract}

Em que pese a reiteração do termo "arranjo", o autor menciona as formas de associativismo definidas em normatização nacional e em atuação institucional e tipificadas na administração pública.

No caso brasileiro, há algumas formas de associativismo territorial. Exemplos: arranjos produtivos locais, Comitês de Bacia, Regiões Metropolitanas ou pactos metropolitanos, os Territórios da Cidadania, Regiões Integradas de Desenvolvimento, e, sobretudo, na maioria dos casos, consórcios, sejam administrativos ou de direito privado, sejam os recém-criados Consórcios Públicos. (p. 23)

\title{
É objetivamente sobre a última tipologia que o autor discorre acerca dos pro-
} cessos e condicionalidades que levam à consolidação de uma ação institucional cooperativa, coordenada, sustentada em pactuação formal, com estruturas de funcionamento e controle típicos da administração pública:

Antes de focar nesse novo modelo, vale citar quais são os fatores que levam ao sucesso do associativismo territorial. De maneira geral, é preciso que haja, em primeiro lugar, mecanismos que reduzam a desconfiança política entre os municípios, dando estabilidade institucional à parceria. Em segundo, é muito importante o apoio dos governos federal e estadual, em virtude da fragilidade gerencial e da falta de recursos dos municípios. Igualmente essencial é a orientação dos arranjos territoriais para uma gestão em rede e direcionada a resultados, criando, de um lado, mecanismos para articular projetos conjuntos e, de outro, para administrar conforme metas e indicadores previamente definidos. Este último ponto põe em evidência que o sucesso das formas de consorciamento intergovernamental depende de um modelo institucional bem gerido, capaz de ser inovador na forma e no conteúdo das políticas. Em suma: a criação do associativismo depende de um modelo administrativo. (ABRUCIO, op. cit., p. 24, grifo nosso)

É precisamente nesse último aspecto destacado no artigo que se explicita a intencionalidade dos chamados Arranjos de Desenvolvimento da Educação (ADE), conforme argumenta o próprio autor no trecho a seguir:

Educ. Soc., Campinas, v. 34, n. 124, p. 803-828, jul.-set. 2013 
Segundo parecer de Mozart Neves Ramos (2011) entregue ao Conselho Nacional de Educação (CNE), o objetivo central de um ADE é desenvolver uma metodologia para apoiar municípios a alavancar ações e indicadores educacionais, visando à melhoria da qualidade da Educação no âmbito local e promovendo o fortalecimento do Regime de Colaboração. (Idem, ibid., p. 27; grifo nosso)

O conselheiro Mozart Neves Ramos, portanto, tem a exata noção dos limites de sua proposição dentro dos marcos legais vigentes para a ação pública. Também denota claramente a constatação de que a forma associativa própria é a de consórcio público, conforme menciona no artigo "Arranjos de Desenvolvimento da Educação", na mesma publicação: "Uma das maneiras que melhor representa o estágio de amadurecimento da Federação brasileira é o consórcio público intermunicipal, que, por isso, conta com capítulo próprio neste livro (ver 'Associativismo territorial para a coordenação intergovernamental')" (RAMOS, 2012, p. 17).

No artigo "Implementando Arranjos de Desenvolvimento da Educação", no mesmo livro, Tereza Perez, Roberta Panico e Paola Gongra avançam na descrição dos processos e percepções que levaram à formulação sistemática desses Arranjos, e intencionalidades para influenciar políticas públicas de alcance nacional.

Um ADE é uma modalidade de trabalho em rede, na qual um grupo de municípios com proximidade geográfica e necessidades semelhantes busca trocar experiências para solucionar conjuntamente dificuldades daquele território na área da Educação, promovendo e fortalecendo a cultura do planejamento integrado e colaborativo.

A adequação de nossas práticas de formação intermunicípios à proposta dos Arranjos e à oportunidade representada pelo PAR nos levou em 2009, juntamente com a Fundação Vale, a iniciar uma cooperação com o movimento Todos Pela Educação e o Ministério da Educação (MEC). O trabalho começou com a definição dos municípios que constituiriam os territórios de atuação. Em seguida, analisamos as notas atribuídas ao PAR de cada município e os indicadores educacionais, de modo a evidenciar onde estavam as maiores fragilidades do território.

Visitamos os municípios para apresentar a análise dos dados educacionais aos prefeitos e secretários municipais de Educação, e os convidamos para uma reunião com os demais representantes dos municípios, na qual elaboramos um plano para atuação conjunta que tinha o PAR como eixo estruturante. (PEREZ; PANICO; GONGRA, 2012, p. 87-88)

Não é qualquer acaso a autoria das iniciativas e a trajetória percorrida sob a legitimação de uma política organizada nacionalmente, na perspectiva de fortalecimento da cooperação federativa, num contexto de maior comprometimento da União e de maior disponibilidade de recursos para a assistência técnica e financeira, através do Fundo Nacional de Desenvolvimento da Educação (FNDE), associada à ampliação dos recursos diretamente transferidos para a manutenção e desenvolvimento da educação básica e valorização do magistério pela via do Fundeb. As autoras contabilizavam 105 municípios entre os estados do Pará (16), Maranhão (20), 
Tocantins (12), Sergipe (5), Minas Gerais (32) e Paraná (20), ano de 2012, como “Arranjos Comunidade Educativa Cedac" (idem, ibid.; grifo nosso).

Obviamente que tamanha diversidade de situações implica contratos dispersos, inúmeros entraves de mobilidade e de contratação de pessoas, contatos e agendamentos, cobertura de despesas e reuniões e eventos que incluíam pessoal da organização privada e dos agentes públicos e servidores. Para além das assessorias técnicas, a disseminação de valores - e, por eles, dos fins da educação - também é latente na transcrição a seguir:

Acreditamos que a organização dos municípios em ADEs seja um passo significativo para a melhoria da Educação no País. Se os encontros com os técnicos das secretarias ocorrem bimestralmente e duram dois dias e meio, com um período exclusivo para o debate com os secretários de Educação, o mesmo ocorre com o grupo de gestores escolares. Na semana do encontro, aproveitamos uma das noites para exibir um filme do circuito comercial, com a intenção de ampliar o universo cultural e discutir as relações interpessoais que envolvem atitudes e valores em torno da trama da narrativa. Esse momento tem sido essencial para criar a cultura de grupo e possibilitar a análise das atitudes tomadas pelas personagens do filme e sua correlação com o tratamento dado aos alunos, ao espaço, à diversidade, à cultura e ao meio ambiente, entre tantos outros temas. Ao trazer uma história aparentemente externa, a intenção é ampliar o olhar para a realidade local. Trata-se de uma forma de analisar e de estar consciente do significado de muitas das nossas ações, sejam elas no âmbito profissional, sejam no pessoal.

Como se pode conferir, as narrativas até aqui, do ponto de vista da organização da oferta de educação pública básica, não trouxe a interação com redes estaduais ou federal existentes nesses mesmos territórios. As interações se dão explicitamente com redes municipais, reduzindo bastante a consideração territorial conforme sugerida pela Constituição Federal e sustentada nas argumentações do próprio Abrúcio (2012) no primeiro artigo. Não é por acaso que os chamados ADEs passam a ser substitutos dos entes federativos municipais na reclamação do diálogo com estados e a União, como se lê na sequência: “[...] estados e o MEC dialogarem com os municípios por intermédio de ADEs, certamente haverá maior interlocução e compreensão das necessidades territoriais diante das diversidades culturais, sociais, econômicas, ambientais e educacionais".

Em outra perspectiva de abordagem, Eliane Baltazar Godoi e Eliana A. M. M. Breyer, do ADE Noroeste Paulista (Votuporanga), dando consequência à metodologia em curso na região, anotam:

Ficou claro, porém, que para avançar na elaboração do planejamento estratégico e na realização das projeções de trabalho, será necessário buscar novos parceiros. Quanto à organização dos trabalhos do $\mathrm{ADE}$, ficou estabelecida a realização de quatro fóruns anuais para discussões e troca de experiências educacionais, acompanhados da entrega de relatórios municipais individuais de acompanhamento do PAR, nos quais deverão 
ser apontados os indicadores em que ocorreram avanços das ações propostas. (GODOI; BREYER, 2012, p. 99-100)

Para ilustrar a gama de objetivos estratégicos e a lista de parcerias, visando alcançar a consecução das ações, vale considerar as que selecionamos para esse artigo:

Buscar parceiros financiadores em sistema de cooperação mútua: Unesco, Unicef, Petrobrás, Instituto Ayrton Senna, Fundação Itaú Social, governo federal, para atender às necessidades de construção de centros de estudo, contratação de equipes (monitores e educadores), aquisição de laboratórios de ciências, material pedagógico voltado para a prática de esportes, lazer e artes, aquisição de livros para bibliotecas escolares e adequação de espaços para atividades de esportes, ciências, lazer e artes nas escolas municipais.

Buscar parceiros capacitadores em sistema de cooperação mútua: Fundação Lemmam, Fundação Maria Cecília Vidigal, Fundação Educacional de Votuporanga/Unifev, Instituto Federal de Educação, Ciências e Tecnologia de São Paulo/IFSP, Universidade Camilo Castelo Branco/Unicastelo, Fundação Educacional de Fernandópolis, Fundação Educacional de Santa Fé do Sul.

Outra narrativa, presente no livro organizado por Abrucio e Ramos, é apresentada por Cybele Amado de Oliveira e Cristina Meirelles, do Instituto Chapada de Educação e Pesquisa, sediado no estado da Bahia. O percurso apresenta as iniciativas de assessoria articulada entre voluntários que levaram à formação do Instituto e o alcance de suas ações de assessoramento de grande amplitude sobre as redes municipais de ensino na região de abrangência. Fundamentalmente, o Instituto exerce atividades de mobilização social, de planejamento, de formação continuada, de organização e controle curricular, de avaliação e monitoramento, como se pode ler a seguir:

Responsáveis pelo projeto e parceiros iniciam o debate sobre a necessidade de institucionalização do trabalho. Um grupo de voluntários (representantes das secretarias de Educação, associações e coordenadores) inicia a elaboração do estatuto; com o foco e os objetivos do que seria o Icep surgiram novas estratégias construídas e consolidadas pelo ADE Chapada e Semiárido:

- $\quad$ oficinas pedagógicas para supervisores e diretores pedagógicos alocados nas secretarias para formar equipe técnica qualificada (diretores pedagógicos e supervisores técnicos) e garantir a sustentabilidade da formação continuada em todos os municípios;

- oficinas pedagógicas para coordenadores pedagógicos do grupo 2005 de primeira a quarta séries (atuais primeiro ao quinto anos), e introdução à formação de coordenadores de quinta a

- oitava séries (atuais sexto ao nono anos) com foco na leitura e na escrita;

- $\quad$ ampliação da equipe de formadores com o objetivo de instruir formadores regionais;

- $\quad$ seminários internos (grupo de diretores pedagógicos e de supervisores técnicos) com o tema "Da sala de aula às políticas públicas"; 
- grupos quinzenais de análise e reflexão da prática com professores, coordenadores e diretores pedagógicos e escolares;

- $\quad$ organização dos planos de ação pelos coordenadores e diretores e de projetos didáticos e institucionais;

- $\quad$ organização de Conselhos de Classe para acompanhamento e alimentação do processo de ensino e aprendizagem;

- jornadas pedagógicas ministradas pelos coordenadores pedagógicos municipais. (OLIVEIRA; MEIRELLES, 2012, p. 117-118)

Importante matéria com detalhamentos sobre os percursos feitos pela metodologia patenteada como ADE pode ser acessada em: <http://revistaescolapublica. uol.com.br/textos/19/artigo246415-1.asp>. Nela, pode-se ver um quadro ilustrativo dos procedimentos mais característicos da conformação de um ADE. Ressalto, também, as considerações reiteradas de especialistas entrevistados sobre a oportunidade dada pelo PAR, as limitações estruturais de administrações municipais, os ganhos de escala para os parceiros e a intencionalidade de contornar as regras da ação pública para assegurar certa qualidade da educação pública municipal. Por exemplo, na matéria citada:

De acordo com Cesar Callegari, membro do Conselho Nacional de Educação, o modelo tem origem nos Arranjos Produtivos Locais, formulados há mais de dez anos, para processos de cooperação entre empresas de determinada cadeia produtiva e o poder público. "Mais recentemente, essa ideia voltou a se apresentar como solução por dois lados: pelo setor público e por empresas. No caso da educação, os arranjos têm foco em desenvolvimento no lugar de produção", explica.

Um de seus parceiros em programas de assessoria educacional a redes municipais, encarregado de superar descontinuidades e assegurar escala no serviço contratado, completa:

O especialista em gestão de políticas públicas municipais Sinoel Batista, que trabalha no Instituto Brasileiro de Sociologia Aplicada (Ibsa), está encarregado de colaborar para identificar uma estrutura que garanta perenidade aos arranjos.

"A instância que melhor atende a estruturação dos ADEs é o consórcio público. Apresentei a sugestão e esta passou a ser a ferramenta para estruturar os arranjos", afirma Batista. Até o momento, nenhuma das quatro experiências acompanhadas pelo TPE instituiu consórcio público e há chances de que o arranjo do noroeste de São Paulo se torne o primeiro a fazê-lo."

Este mesmo especialista avança na informação sobre a estratégia em curso para alcançar a transferência de recursos públicos federais diretamente a essas estruturas, como se constituíssem um ente federativo em substituição aos municípios ou uma antecipação informal de consórcios: 
Outro conceito que fornece elementos para entender os arranjos como política pública é o do associativismo territorial. $\mathrm{O}$ desenho da metodologia de implementação e estrutura de funcionamento do ADE não está finalizado, mas há a preocupação de torná-lo uma ferramenta de gestão pública reconhecida pelo MEC.

A institucionalização contribui para orientar os municípios a definir como será feito o ADE, além de explicitar o conceito e o contexto político-estratégico no qual se insere.

É o próximo trecho, atribuído ao próprio Callegari, que empresta razão completa ao "atalho empresarial" no citado artigo de Araujo (2012), como se lê:

"Investigamos as possibilidades de aproveitamento de recursos do Fundo de Manutenção e Desenvolvimento da Educação Básica e de Valorização dos Profissionais da Educação (Fundeb). Estamos em fase de estudos, para elaborar orientações", afirma Callegari.

Mais explícita, igualmente, é a narrativa de Cruz (2012, p. 147) no artigo “Contribuição para o fortalecimento do Regime de Colaboração", na coletânea de textos organizada por Abrucio e Ramos (2012) mencionada anteriormente:

Entretanto, a experiência vem mostrando que essas unidades da Federação representam a fatia mais frágil da configuração geopolítica e administrativa brasileira, em função de limitações orçamentárias, ausência de quadros técnicos, graves problemas de descontinuidade política, entre outros fatores. Criar mecanismos que promovam a cooperação entre eles pode representar um passo decisivo para vencer essas limitações e estabelecer condições para assegurar a oferta de uma educação de qualidade nas duas primeiras etapas da Educação Básica.

Assim, foi reconhecendo a fragilidade desse ente federativo e a necessidade de fortalecê-lo em função do papel estratégico que exerce na oferta educacional que institutos e fundações de empresas vêm promovendo, cada vez mais, um número maior de ações no campo da Educação em parceria com os municípios. Os investimentos hoje, segundo os últimos números do Grupo de Institutos e Fundações de Empresas (Gife), giram em torno de dois bilhões de reais. Esse trabalho de corresponsabilidade social dos institutos e fundações com os municípios também vem promovendo e provocando um maior envolvimento da sociedade com o desafio da educação de qualidade.

[...] Os ADEs seriam, assim, instrumentos indutores de cooperação e colaboração entre municípios, articulados com os estados e a União, e contando, quando necessário, com a contribuição transversal dos institutos e fundações [...].

A riqueza de detalhes da narrativa, entretanto, faz merecer uma transcrição mais completa do artigo, tendo em vista a revelação clara da ação estratégica e articulada em diversos ambientes institucionais e o êxito dos empreendimentos para forjar uma nova institucionalidade que transponha os limites da administração pública, as exigências da conformação de consórcios, o abandono da articulação com os estados e a redução do território à administração de redes municipais de ensino, terceirizando tarefas próprias da condução de sistemas às assessorias estratégicas com escala, estabilidade contratual e orçamento disponível. Uma privatização por dentro 
da rede, não concorrente com ela, num atalho de regras flexíveis de nova combinação institucional, para além da Resolução do Conselho Nacional de Educação.

Observe-se o passo a passo:

No Projeto de Lei n. 8.035/2010, relativo ao novo PNE e em tramitação no Congresso Nacional, foi incorporado o modelo de ADE como mecanismo eficaz para o fortalecimento do Regime de Colaboração, conforme as Emendas ao Substitutivo descritas a seguir:

Emenda ao Substitutivo n. 74: propõe acrescentar $\S 5^{\circ}$ ao art. $6^{\circ}$ do Substitutivo com a previsão de que o "fortalecimento do Regime de Colaboração horizontal entre municípios, articulado com o Regime de Colaboração vertical envolvendo estados e União, pode ser implementado mediante Arranjos de Desenvolvimento da Educação". Aprovada, na forma do inciso XI do art. $2^{\circ}$ por sua importância. Regime de Colaboração deve figurar como diretriz.

Emenda ao Substitutivo n. 95: acrescenta dois parágrafos. No primeiro, prevê a criação de instância permanente de negociação e cooperação entre os entes federados; no segundo, prevê a possibilidade de organização das políticas por meio de ADEs, ou seja, de cooperação entre municípios. A emenda é acatada, nos termos da redação adotada no novo Substitutivo. É salutar prever a existência legal desse espaço interinstitucional. A institucionalização dos Arranjos merece ser incentivada. (CRUZ, op. cit., p. 149)

Sua conclusão não poderia ser mais entusiasmada. Com a perspectiva sucessivamente vitoriosa na associação de instrumentos normativos que alcançam a forma de lei, os sinais apontam para a conformação tipificada de conglomerados mais especializados capazes de dar vazão à nova escala em projeto e em disputa, reduzindo seus riscos, é claro. Não é difícil de perceber pelo que segue:

Isso representa uma mudança de cultura, que exige não apenas tempo para se consolidar, mas também disciplina e organização permanentes. Isso, por sua vez, vai exigir dos institutos e fundações uma reorganização na forma de atuação, no sentido de uma maior articulação e cooperação, evitando as indesejáveis sobreposições. Assim, um dos desafios é a necessidade de criar uma estrutura, possivelmente um instituto específico ou conselho, capaz de articular institutos e fundações no processo de estruturação e implementação, quando requerido, dos ADEs locais. O processo de articulação e de cooperação poderia ser implementado mediante o aval das várias instituições apoiadoras dos Arranjos, que, a priori, poderiam ser identificadas em três grupos distintos:

Grupo 1: Todos pela Educação, Comunidade Educativa Cedac, Instituto Chapada, Instituto Mind Group e Fundação Getúlio Vargas de São Paulo, entre outras, cujo papel seria mais de mobilização, fomento de estudos, formação in loco e desenvolvimento do modelo.

Grupo 2: Fundação Vale, Instituto Natura, Fundação Lemann, Instituto Gerdau, Instituto Votorantim, Mindlab e Fundação Itaú Social, entre outras, cujo papel seria o da corresponsabilidade social na gestão e no financiamento.

Grupo 3: instituições internacionais, como a Unesco, que poderiam contribuir como observadores externos do processo de implantação e de funcionamento dos Arranjos. (Idem, ibid., p. 150) 
Aqui se identificam muitíssimo bem as intencionalidades por trás das palavras da Portaria n. 1.238, de 11 de outubro de 2012 e suas sucedâneas. Na visão da articulista, vislumbram-se as conclusões do Grupo de Trabalho no âmbito da Secretaria de Articulação com os Sistemas de Ensino do Ministério da Educação:

\begin{abstract}
Naturalmente, todo esse trabalho deve ser conduzido com a estreita participação e colaboração da União Nacional dos Dirigentes Municipais de Educação (Undime), do Conselho Nacional dos Secretários de Educação (Consed), do Conselho Nacional de Educação (CNE) e do Ministério da Educação (MEC). No entanto, é preciso que o próprio MEC, como responsável direto pelas macropolíticas de educação no País, se organize internamente em termos de uma Portaria, por exemplo, capaz de definir a responsabilidade de suas secretarias internas, mais precisamente a Secretaria de Educação Básica (SEB) e a Secretaria de Articulação com os Sistemas de Ensino (Sase), de forma que os ADEs sejam tratados, de fato, como uma política pública articulada de Estado, em consonância com a homologação do Parecer e Resolução do CNE feitos pelo próprio MEC.
\end{abstract}

Há quem, entretanto, vislumbre coincidir essas teses dos Arranjos de Desenvolvimento da Educação com os Programas de Desenvolvimento Regional Sustentável, derivados de empreendimentos de grande impacto promovidos por investimentos públicos diretos e incentivados por Fundos de Desenvolvimento Regional com recursos orçamentários, concessão de financiamento em condições especiais a empreendimentos privados e, mesmo, parcerias público-privadas. Cabe, nesse caso, advertir que, diferentemente dessa compreensão aparentemente ingênua, há distinções constitucionais e institucionais das iniciativas bem conhecidas e não delegáveis. Numa rápida visita auxiliar à Constituição Federal, para além do que comumente tratamos em artigos sobre cooperação federativa, organização da educação nacional e Sistema Nacional de Educação, ganham relevo os seguintes ordenamentos:

Art. 43. Para efeitos administrativos, a União poderá articular sua ação em um mesmo complexo geoeconômico e social, visando a seu desenvolvimento e à redução das desigualdades regionais.

$\S 1^{\text {o }}$ - Lei complementar disporá sobre:

I - as condições para integração de regiões em desenvolvimento;

II - a composição dos organismos regionais que executarão, na forma da lei, os planos regionais, integrantes dos planos nacionais de desenvolvimento econômico e social, aprovados juntamente com estes. (BRASIL, 1988)

No âmbito dos estados-membros, o texto constitucional é claro também:

Art. 25. Os Estados organizam-se e regem-se pelas Constituições e leis que adotarem, observados os princípios desta Constituição. [...].

$\S 3^{\circ}$ - Os Estados poderão, mediante lei complementar, instituir regiões metropolitanas, aglomerações urbanas e microrregiões, constituídas por agrupamentos de municípios 
limítrofes, para integrar a organização, o planejamento e a execução de funções públicas de interesse comum. (Idem, ibid.)

A reconhecida fragilidade dos municípios, entretanto, merece ser mirada com maior atenção. Diferentemente da União e dos estados, que têm a obrigação de manter suas próprias instituições de educação básica e superior, de maneira distinta, as competências municipais apresentam a manutenção de programas, abrindo leituras para uma gama de possibilidades de organização da oferta educacional pública na educação infantil e no ensino fundamental. A Emenda Constitucional n. 53, de 2006, ocupou-se de inserir a cooperação da União, mas não alterou a distinção entre manter programas e manter instituições de ensino. O texto reconhece sub-repticiamente que há municípios em condições tão precárias que não alcançariam a conformação de uma rede própria, obrigatoriamente, em consonância com o princípio da coordenação e da cooperação federativas e da colaboração entre sistemas de ensino. Se há autoridades que não perceberam, toda a narrativa analítica feita nesse artigo pretendeu apontar a ação estratégica em curso na disputa pelo fundo público ampliado, pelo controle da administração, dos fins educacionais e do conteúdo da qualidade segundo os propósitos de quem mobiliza, assessora, planeja, avalia, forma, subsidia, detém os meios de produção e instrumentaliza a política pública para a eficiência econômica.

Art. 30. Compete aos Municípios:

VI - manter, com a cooperação técnica e financeira da União e do Estado, programas de educação infantil e de ensino fundamental;

VII - prestar, com a cooperação técnica e financeira da União e do Estado, serviços de atendimento à saúde da população; [...]. (BRASIL, 1988)

Uma carona dos ADEs no Plano Nacional de Educação tenta, também, superar uma dificuldade processual. A iniciativa da lei é do Poder Executivo.

Art. 165. Leis de iniciativa do Poder Executivo estabelecerão:

$\S 4^{\mathrm{o}}$ - Os planos e programas nacionais, regionais e setoriais previstos nesta Constituição serão elaborados em consonância com o plano plurianual e apreciados pelo Congresso Nacional. (Idem, ibid.)

Alguns contornos do SNE a ser criado em lei, até dois anos depois da sanção do PNE, estão delineados e merecerão atenção para compatibilizar suas atribuições com organismos já existentes, instâncias normativas de controle e acompanhamento já implementadas, formas de colaboração já regulamentadas e outras em debate legislativo concomitante (ABICALIL, 2013). O fato é que não há uma relação direta e simples entre a atribuição dos sistemas e níveis de ensino, ou de vínculo da rede pública com um sistema municipal e da rede privada com o sistema estadual, ou 
de alguma modalidade de oferta com um ente federativo específico. Há, sim, uma interpenetração que guarda vínculos cruzados com o ente que mantém redes em cada nível de ensino e a rede privada, de acordo com a etapa e nível de educação que estes ofertam, com sistemas diferentes. O relatório do PNE não vincula fóruns e conferências estaduais, distritais e municipais aos planos e aos sistemas nesses níveis, por exemplo. A vinculação é sempre com o PNE, o que pode representar mais uma fragmentação.

A seleção de atenções que é indicada aqui guarda direta relação com os temas atinentes aos contornos apontados para o Sistema Nacional de Educação, a cooperação federativa e a colaboração entre sistemas de ensino, não somente por suas ementas oficiais, mas, sobretudo, por seus conteúdos. Assim, a preservação de condições essenciais de afirmação do SNE deve levar em conta os fios em movimento nesse tecido. O aprofundamento da fragmentação e da dispersão não é desejável. O cenário da decisão política ainda está enredado por iniciativas fragmentadas que interferirão intensamente na sua composição, não apenas nas matérias concorrentes, cuja seleção temática procuramos apresentar.

Além de tratar competências comuns, aponta para a consideração das condicionalidades para o exercício das autonomias e da complementaridade em cada âmbito federativo interdependente. Com a nova redação constitucional, a educação básica (especialmente, no âmbito obrigatório) é competência comum das três esferas da administração, ultrapassando os limites administrativos das redes. Assim sendo, mais do que a divisão de competências, trata-se da normatização das condicionalidades operativas que determinem as formas e critérios da cooperação em cada uma. Ademais, o princípio de complementaridade supõe a clareza na definição de normas operacionais básicas vinculantes - já presentes no Sistema Único de Saúde (SUS) e no Sistema Único de Assistência Social (Suas) -, a partir das quais se estabelecem o exercício da autonomia relativa, por um lado, e da cooperação federativa, por outro. Acredito que seja próprio falar da hierarquização das atribuições e competências (para além das legislativas) já previstas na Constituição e na Lei de Diretrizes e Bases da Educação (LDB), colocando luzes sobre os significados operacionais diferentes para as tarefas distributivas e supletivas no que tange ao financiamento (e à União, particularmente) e às ações de assistência técnica e financeira da União e dos estados, diante das condições de realização do direito à educação em meio à diversidade e à desigualdade presentes entre os diversos entes federados.

A disputa final em torno da redação da Meta 20 no PLC n. 103 de 2012 (PNE), em tramitação no Senado Federal, espelha limpidamente as dimensões significadas dessa nova forma de capturar políticas e espaços públicos. Também está associado a essas brechas o conjunto de oportunidades a serem viabilizadas com os recursos derivados da exploração de petróleo e gás, para além dos royalties e dos rendimentos 
do fundo social, como se apresentam nesse momento. Só a parcela transferida pela União, na pior das hipóteses, decuplicaria. Além destes, haverá os recursos adicionais aos vinculados constitucionalmente sob a administração de estados e municípios. Ainda estão presentes os constrangimentos da Lei de Licitações e de Responsabilidade Fiscal, como afirmamos inicialmente. Adicionam-se as disposições do artigo 213 da Constituição Federal, admitindo a transferência direta para instituições privadas sem finalidade lucrativa e sem limites de reversão pública, no caso de cursos de extensão oferecidos por instituições de ensino superior, agora contempladas no Pronatec.

As disposições da reforma administrativa recepcionadas pela Emenda Constitucional n. 19, de 1998, também favorecem variadas formas de organização da prestação de serviço público de maneira indireta, por meio de fundações, autarquias, empresas de terceirização, organizações sociais, organizações de interesse público. Por outro lado, há a pressão dos órgãos de controle como os Tribunais de Conta, enveredando por consideração da eficiência do serviço educacional como critério de análise das contas públicas e, à sua volta, o alargado mercado de consultorias e assessorias educacionais como jamais visto. Isso é resultado do crescimento econômico, com repartição da renda, aumento da massa salarial dos trabalhadores, redução de juros básicos, liberação de recursos orçamentários anteriormente despendidos com a dívida pública para políticas públicas de desenvolvimento social sustentável. Tais pautas tornam ainda mais presentes e atuais as abordagens em torno da conformação do Sistema Nacional de Educação.

Como a organização da educação nacional não se deu meramente por níveis ou etapas, nem automaticamente pela administração direta de redes públicas ou da vinculação normativa das instituições privadas, alguma ordem é reclamada para não se submeter à simples concorrência de competências à luz da consideração da educação como direito universal e da educação básica como direito público subjetivo.

Se entendido assim, o passo para a construção de um sistema nacional deve considerar, no caso brasileiro, além de quem faz o quê: sob quais condições faz; com que mediações de complementaridade e assistência; com que reciprocidade normativa; com que transitoriedades; sob qual regramento; e por deliberação de que órgão, instância ou ente? Vale lembrar que, também, se aplica no Brasil o princípio da subsidiariedade, muito bem exemplificado pelo Programa Universidade para Todos (Prouni), Programa Nacional de Acesso ao Ensino Técnico e Emprego (Pronatec), Programa Nacional de Educação do Campo (Pronacampo), Certificação das Entidades Beneficentes da Assistência Social (Cebas), Política Nacional de Formação (PNF), e variadas ações coordenadas e financiadas por diversos órgãos públicos, nas três esferas de governo. 
Há ebulição suficiente para forjar novas estruturas e relações institucionais democráticas. Se dúvidas houve, as ruas o disseram bem recentemente.

\section{Referências}

ABICALIL, C.A. Federalismo e Sistema Nacional de Educação. In: SEMINÁRIO DA EDUCAÇÃO BRASILEIRA, 4., 2013, Campinas. E-Book... Campinas: Cedes, 2013. (No prelo).

ABICALIL, C.A. A Conae e o novo PNE Novos marcos para a educação. Retratos da Escola, Brasília, DF, v. 4, n. 6, p. 11-25, jan./jun. 2010.

ABRÚCIO, F.L. A dinâmica federativa da educação brasileira: diagnóstico e propostas de aperfeiçoamento. In: OLIVEIRA, R.P.; SANTANA, W. (Org.). Educação e federalismo no Brasil: combater as desigualdades, garantir a diversidade. Brasília, DF: Unesco, 2010. p. 39-70.

ABRÚCIO, F.L. Associativismo terrritorial para a coordenação intergovernamental. In: ABRUCIO, F.L, RAMOS, M.N. (Org). Regime de colaboração e associativismo territorial: arranjos de desenvolvimento da Educação. São Paulo: Moderna, 2012. p. 17-30.

ABRÚCIO, F.L.; RAMOS, M.N. (Org.). Regime de colaboração e associativismo territorial: arranjos de desenvolvimento da Educação. São Paulo: Moderna, 2012.

ARAUJO, G.C. Direito à educação básica: a cooperação entre os entes federados. Retratos da Escola, Brasília, DF, v. 4, n. 7, p. 231-241, jul./dez. 2010.

ARAUJO, G.C. Federalismo cooperativo e arranjos de desenvolvimento da Educação: o atalho silencioso do empresariado para a definição e regulamentação do regime de cooperação. Revista Brasileira de Política e Administração da Educação, Porto Alegre, v. 28, n. 2, p. 515-531, maio/ago. 2012. Disponível em: <http://seer.ufrgs.br/ rbpae/article/view/37419/24160>. Acesso em: mar. 2013

BRASIL. Constituição (1988). Constituição da República Federativa do Brasil. Brasília, DF: Senado Federal, 1988. Disponível em: <http://www.planalto.gov.br/ccivil_03/ Constituicao/Constituicao.htm>. Acesso em: mar. 2013.

BRASIL. Emenda Constitucional n. 53, de 19 de dezembro de 2006. Dá nova redação aos arts. 7º , 23, 30, 206, 208, 211 e 212 da Constituição Federal e ao art. 60 do Ato das Disposições Constitucionais Transitórias. Diário Oficial da União, Brasília, DF, 20 dez. 2006. Disponível em: <http://www.planalto.gov.br/ccivil_03/constituicao/emendas/ emc/emc53.htm>. Acesso em: jun. 2012.

BRASIL. Emenda Constitucional n. 59, de 11 de novembro de 2009. Acrescenta § 3ㅜ ao art. 76 do Ato das Disposições Constitucionais Transitórias para reduzir, anualmente, 
a partir do exercício de 2009, o percentual da Desvinculação das Receitas da União incidente sobre os recursos destinados à manutenção e desenvolvimento do ensino de que trata o art. 212 da Constituição Federal, dá nova redação aos incisos I e VII do art. 208, de forma a prever a obrigatoriedade do ensino de quatro a dezessete anos e ampliar a abrangência dos programas suplementares para todas as etapas da educação básica, e dá nova redação ao $\S 4^{\circ}$ do art. 211 e ao $\S 3^{\circ}$ do art. 212 e ao caput do art. 214, com a inserção neste dispositivo de inciso VI. Diário Oficial da União, Brasília, DF, 12 nov. 2009. Disponível em: <http://www.planalto.gov.br/ccivil_03/constituicao/ emendas/emc/emc59.htm>. Acesso em: jun. 2012.

BRASIL. Lei n. 8.080, de 19 de setembro de 1990. Dispõe sobre as condições para a promoção, proteção e recuperação da saúde, a organização e o funcionamento dos serviços correspondentes e dá outras providências. Diário Oficial da União, Brasília, DF, 20 set. 1990a. Disponível em: <https://www.planalto.gov.br/ccivil_03/leis/18080. htm>. Acesso em: mar. 2013.

BRASIL. Lei n. 8.142, de 28 de dezembro de 1990. Dispõe sobre a participação da comunidade na gestão do Sistema Único de Saúde (SUS) e sobre as transferências intergovernamentais de recursos financeiros na área da saúde e dá outras providências. Diário Oficial da União, Brasília, DF, 31 dez. 1990b. Disponível em: <http://www. planalto.gov.br/ccivil_03/leis/18142.htm>. Acesso em: mar. 2013.

BRASIL. Lei n. 8.742, de 7 de dezembro de 1993. Dispõe sobre a organização da Assistência Social e dá outras providências. Diário Oficial da União, Brasília, DF, 8 dez. 1993. Disponível em: <https://www.planalto.gov.br/ccivil_03/leis/18742.htm>. Acesso em: jun. 2013.

BRASIL. Lei n. 9.394, de 20 de dezembro de 1996. Estabelece as diretrizes e bases da educação nacional. Diário Oficial da União, Brasília, DF, 23 dez. 1996. Disponível em: $<$ http://www.planalto.gov.br/ccivil_03/Leis/L9394.htm>. Acesso em: jun. 2013.

BRASIL. Lei n. 11.096, de 13 de janeiro de 2005. Institui o Programa Universidade para Todos - Prouni, regula a atuação de entidades beneficentes de assistência social no ensino superior; altera a Lei n. 10.891, de 9 de julho de 2004, e dá outras providências. Diário Oficial da União, Brasília, DF, 14 jan. 2005a. Disponível em: <http://www. planalto.gov.br/ccivil_03/_ato2004-2006/2005/Lei/L11096.htm>. Acesso em: jun. 2012.

BRASIL. Lei n. 11.107, de 6 de abril de 2005. Dispõe sobre normas de contratação de consórcios públicos e dá outras providencias. Diário Oficial da União, Brasília, DF, 7 abril 2005b. Disponível em: <http://www.planalto.gov.br/ccivil_03/_Ato2004-2006/2005/ Lei/L11107.ht>. Acesso em: jul. 2013.

BRASIL. Lei n. 11.494, de 20 de junho de 2007. Regulamenta o Fundo de Manutenção e Desenvolvimento da Educação Básica e de Valorização dos Profissionais da 
Educação - Fundeb, de que trata o art. 60 do Ato das Disposições Constitucionais Transitórias; altera a Lei n. 10.195, de 14 de fevereiro de 2001; revoga dispositivos das Leis n. 9.424, de 24 de dezembro de 1996, 10.880, de 9 de junho de 2004, e 10.845, de 5 de março de 2004; e dá outras providências. Diário Oficial da União, Brasília, DF, 21 jun. 2007. Disponível em: <http://www.planalto.gov.br/ccivil_03/_ato20072010/2007/Lei/L11494.htm>. Acesso em: jun. 2012.

BRASIL. Lei n. 12.101, de 27 de novembro de 2009. Dispõe sobre a certificação das entidades beneficentes de assistência social; regula os procedimentos de isenção de contribuições para a seguridade social; altera a Lei n. 8.742, de 7 de dezembro de 1993; revoga dispositivos das Leis n. 8.212, de 24 de julho de 1991, 9.429, de 26 de dezembro de 1996, 9.732, de 11 de dezembro de 1998, 10.684, de 30 de maio de 2003, e da Medida Provisória n. 2.187-13, de 24 de agosto de 2001; e dá outras providências. Diário Oficial da União, Brasília, DF, 30 nov. 2009. Disponível em: <http://www. planalto.gov.br/ccivil_03/_ato2007-2010/2009/lei/112101.htm>. Acesso em: jun. 2012.

BRASIL. Lei n. 12.513, de 26 de outubro de 2011. Institui o Programa Nacional de Acesso ao Ensino Técnico e Emprego (Pronatec); altera as Leis n. 7.998, de 11 de janeiro de 1990, que regula o Programa do Seguro-Desemprego, o Abono Salarial e institui o Fundo de Amparo ao Trabalhador (FAT), n. 8.212, de 24 de julho de 1991, que dispõe sobre a organização da Seguridade Social e institui Plano de Custeio, n. 10.260, de 12 de julho de 2001, que dispõe sobre o Fundo de Financiamento ao Estudante do Ensino Superior, e n. 11.129, de 30 de junho de 2005, que institui o Programa Nacional de Inclusão de Jovens (ProJovem); e dá outras providências. Diário Oficial da União, Brasília, DF, 27 out. 2011. Disponível em: <http://www.planalto.gov. br/ccivil_03/_ato2011-2014/2011/lei/112513.htm>. Acesso em: jun. 2012.

BRASIL. Lei Complementar n. 101, de 4 de maio de 2000. Estabelece normas de finanças públicas voltadas para a responsabilidade na gestão fiscal e dá outras providencias. Diário Oficial da União, Brasília, DF, 05 maio 2000. Disponível em: <http:// www.planalto.gov.br/ccivil_03/Leis/LCP/Lcp101.htm mRlYiAyMDEzljt9> Acesso em: jul. 2013.

BRASIL. Ministério do Desenvolvimento Social e Combate à Fome. Conselho Nacional de Assistência Social. Resolução n. 130, de 15 de julho de 2005. Aprova a Norma Operacional Básica da Assistência Social - NOB SUAS. Diário Oficial da União, Brasília, DF, 25 jul. 2005.

BRASIL. Ministério da Educação. Portaria , n. 213, de 2 de março de 2011. Aprova a Resolução n. 5, de 22 de fevereiro de 2011, da Comissão Intergovernamental de Financiamento para a Educação Básica de Qualidade. Diário Oficial da União, Brasília, DF, de 03 mar. 2011. Seção 1, pag. 10. Disponível em: <http://www.fnde.gov.br/ 
fnde/legislacao/portarias/item/3591-portaria-mec-no-213-de-02-de-março-de-2011>. Acesso em: jun. 2013.

BRASIL. Ministério da Educação. Portaria n. 344, de 24 de abril de 2013. Dispõe sobre o ajuste anual da distribuição dos recursos do Fundo de Manutenção e Desenvolvimento da Educação Básica e de Valorização dos Profissionais da Educação (Fundeb), no exercício de 2012. Disponível em: <http://www.fnde.gov.br/component/k2/ item/4427-portaria-mec-n ${ }^{\circ}$-344,-de-24deabrilde2013?highlight=YTozOntpOjA7czo2 OiJmdW5kZWIiO2k6MTtpOjIwMTM7aToyO3M6MTE6ImZ1bmRlYiAyMDEzIjt9>. Acesso em: jun. 2013.

CONFERENCIA NACIONAL DA EDUCAÇÃO (CONAE), 2010, Brasília, DF. Documento final. Brasília, DF: MEC, 2010. Disponível em: <http://conae.mec.gov.br/images/ stories/pdf/pdf/documetos/documento_final_sl.pdf>. Acesso em: jun. 2012.

CRUZ, P. Contribuição para o fortalecimento do regime de colaboração. In: ABRUCIO, F.L.; RAMOS, M.N. (Org.). Regime de colaboração e associativismo territorial: arranjos de desenvolvimento da Educação. São Paulo: Moderna, 2012. p. 143-151.

DOURADO, L.F.; AMARAL, N.C. Financiamento e gestão da educação e o PNE 20112020: avaliação e perspectivas. In: DOURADO, L.F. (Org.). Plano Nacional de Educação (2011-2020): avaliação e perspectivas. Goiânia: UFG, 2011. p. 285-315.

GRACINDO, R.V. O Sistema Nacional de Educação e a escola pública de qualidade para todos. Retratos da Escola, Brasília, DF, v. 4, n. 6, p. 53-64, jan.jun. 2010.

MARTINS, P.S. Fundeb, federalismo e regime de colaboração. Campinas: Autores Associados, 2011.

OLIVEIRA, C.A.; MEIRELLES, C. Projeto Chapada: uma experiência de ADE na Chapada Diamantina. In: ABRUCIO, F.L.; RAMOS, M.N. (Org.). Regime de colaboração e associativismo territorial: arranjos de desenvolvimento da Educação. São Paulo: Moderna, 2012. p. 109-128.

PEREZ, T.; PANICO, R.; GONGRA, P. Implementando Arranjos de Desenvolvimento da Educação. In: ABRUCIO, F.L.; RAMOS, M.N. (Org.). Regime de colaboração e associativismo territorial: arranjos de desenvolvimento da Educação. São Paulo: Moderna, 2012. p. 85-98

SAVIANI, D. Sistema de educação: subsídios para a Conferência Nacional de Educação (Conae). In: CONFERÊNCIA NACIONAL DE EDUCAÇÃO, 2010, Brasília, DF. Anais... Brasília, DF: MEC, 2011a. p. 71-93.

SAVIANI, D. Plano Nacional de Educação, a questão federativa e os municípios: o regime de colaboração e as perspectivas da educação brasileira. Grabois, 17 ago. 
2011b. Disponível em: <http://grabois.org.br/portal/revista.int.php?id_sessao=16\&id_ publicacao=447\&id_indice=2559>. Acesso em: 7 jun. 2012.

SPELLER, P. O potencial das políticas educacional e tributária para o desenvolvimento com equidade. In: RONCA, A.C.C.; RAMOS, M.N. (Coord.). Da Conae ao PNE 2011-2020: contribuições do Conselho Nacional de Educação. São Paulo: Moderna, 2010. p. 15-36.

Recebido em 19 de julho de 2013.

Aprovado em 26 de julho de 2013. 